\title{
Bilateral Adrenal Hemorrhage in a Patient with Antiphospholipid Syndrome during Chronic Graft-versus-host Disease
}

\author{
Mariko Minami ${ }^{1,2}$, Tsuyoshi Muta ${ }^{1}$, Masahiro Adachi $^{3}$, Masakazu Higuchi ${ }^{4}$, \\ Kenichi Aoki ${ }^{1}$ and Ryosuke Ogawa ${ }^{1}$
}

\begin{abstract}
:
We present the case of a 56-year-old man with an upper respiratory infection followed by fatigue, hypotension, and hyponatremia. Bilateral adrenal hemorrhage was confirmed, based on T2-weighted magnetic resonance imaging. The patient had previously undergone allogeneic hematopoietic stem cell transplantation and had been diagnosed with antiphospholipid syndrome (APS) during the development of chronic graft-versushost disease. A prompt diagnosis and steroid replacement, in addition to anticoagulant therapy, resulted in a favorable outcome. Once the diagnosis of APS has been confirmed, which might be the sign of bilateral adrenal hemorrhage, the initial manifestations of adrenal insufficiency should never be overlooked.
\end{abstract}

Key words: antiphospholipid antibody syndrome, graft-versus-host disease, adrenal hemorrhage

(Intern Med 57: 1439-1444, 2018)

(DOI: 10.2169/internalmedicine.9820-17)

\section{Introduction}

Autoimmune disorders have been described after allogeneic hematopoietic stem cell transplantation (HSCT); the majority of these syndromes are mediated by autoantibodies (1). Antiphospholipid syndrome (APS) is characterized by elevated titers of antiphospholipid antibodies (aPL), which is known as the lupus anticoagulant (LAC) and/or anticardiolipin antibodies (aCL), as well as by various thrombotic complications (2). A retrospective analysis demonstrated that LAC was detected in $3 \%$ of HSCT recipients (3), and aCL was detected in $10.1 \%$ of patients who developed chronic graft-versus-host disease (GVHD) (4). Moreover, with an incidence of $<1 \%$, bilateral adrenal hemorrhage is a rare complication of APS (2). This is the first report to describe a case of APS during the development of chronic GVHD in a patient whose condition was subsequently complicated by bilateral adrenal hemorrhage. The current report describes the sequence of events, which pro- vides an understanding of the pathophysiology and suggests an appropriate treatment for this serious complication.

\section{Case Report}

In 2003, a 56-year-old man presented with stage IV, grade II follicular non-Hodgkin's lymphoma harboring $\mathrm{t}(14 ; 18)$ $(\mathrm{q} 32 ; \mathrm{q} 21)$, add(6)(p11), add(7)(p15). He was treated with rituximab and chemotherapy within the same year, and achieved a complete response. However, in 2005, he presented with generalized lymphadenopathy and was diagnosed with a relapse. He underwent salvage therapy, which resulted in a partial remission. In 2006, the patient received a total dose of $1.6 \times 10^{9} / \mathrm{kg}$ peripheral blood nucleated cells (mononuclear cells, $1.05 \times 10^{9} / \mathrm{kg} ; \mathrm{CD}^{+} 4^{+}$cells, $5.8 \times 10^{6} / \mathrm{kg}$ ) from a human leukocyte antigen (HLA)-8 locus-identical 57-year-old male sibling with a conditioning regimen consisting of total body irradiation (4 Gy), fludarabine $(150 \mathrm{mg}$ / $\mathrm{m}^{2}$ ) and melphalan $\left(80 \mathrm{mg} / \mathrm{m}^{2}\right)$, and GVHD prophylaxis consisting of cyclosporine and methotrexate (Fig. 1). The pa-

${ }^{1}$ Department of Hematology/Oncology, Japan Community Health Care Organization (JCHO) Kyushu Hospital, Japan, ${ }^{2}$ Department of Medicine and Biosystemic Science, Kyushu University Graduate School of Medicine, Japan, ${ }^{3}$ Department of Endocrinology, Japan Community Health Care Organization (JCHO) Kyushu Hospital, Japan and ${ }^{4}$ Department of Hematology, JR Kyushu Hospital, Japan Received: July 13, 2017; Accepted: September 26, 2017; Advance Publication by J-STAGE: December 27, 2017 Correspondence to Dr. Tsuyoshi Muta, muta0621@gmail.com 


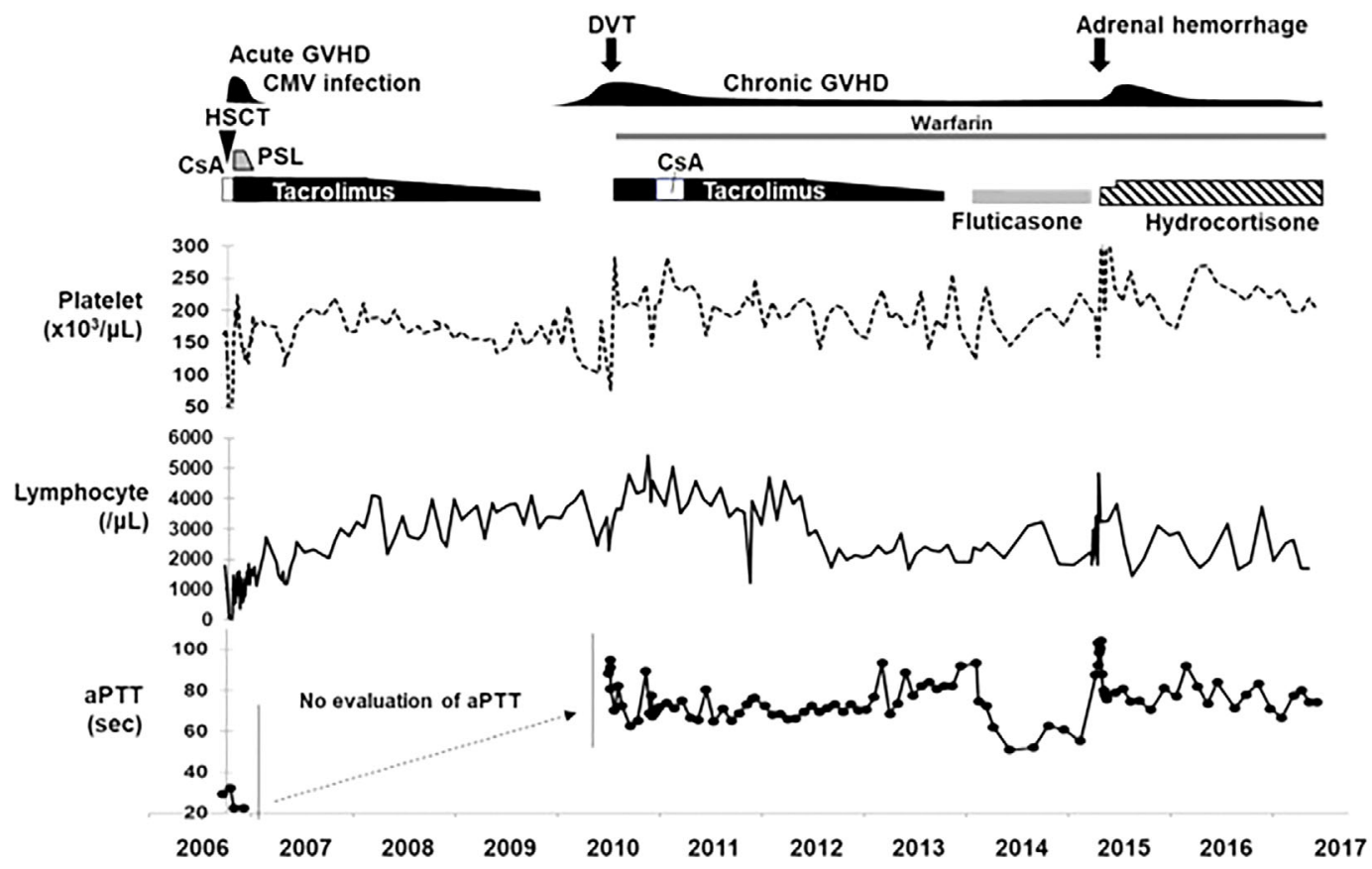

Figure 1. The clinical course after allogeneic hematopoietic stem cell transplantation (HSCT). GVHD: graft-versus-host disease, CMV: cytomegalovirus, CsA: cyclosporine A, PSL: prednisolone, DVT: deep vein thrombosis, aPTT: activated partial thromboplastin time
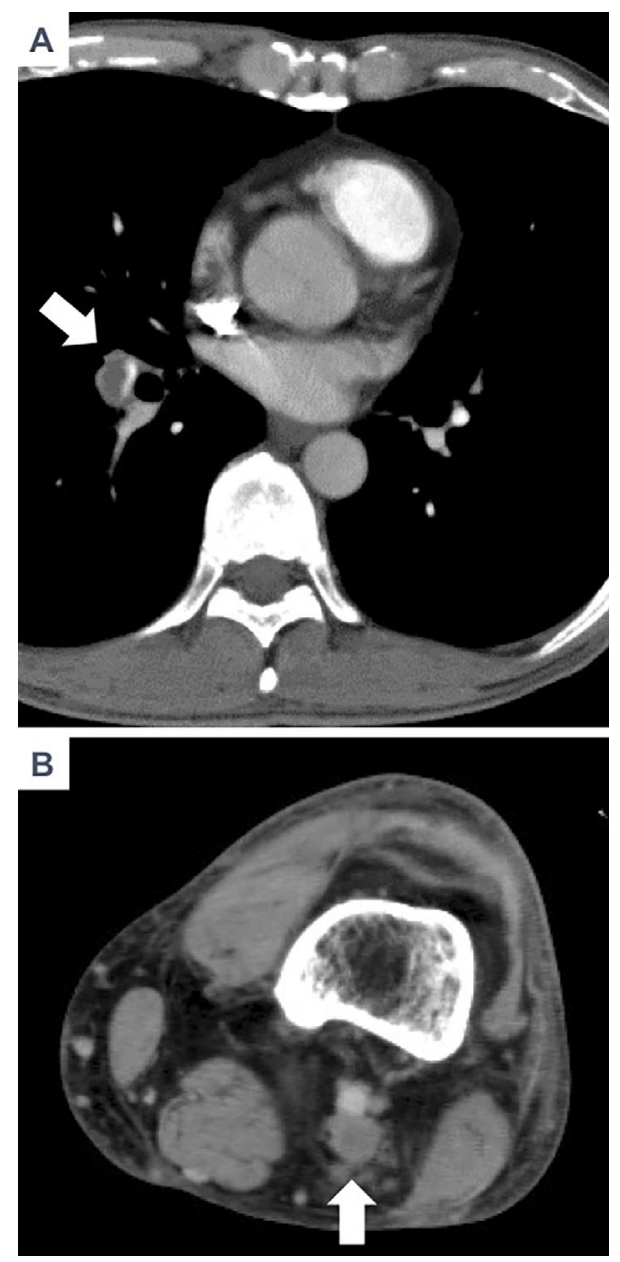

Figure 2. (A) A central pulmonary embolism was confirmed by computed tomography. (B) Femoral vein thrombosis was also confirmed. tient's condition was complicated with grade II acute GVHD of the skin (stage 3) and intestine (stage 1) on day 21 after transplantation and cytomegalovirus (CMV) gastroenteritis, which were treated with prednisolone, tacrolimus, and ganciclovir. There were no abnormalities in the platelet count or in the results of coagulopathy screening before transplantation. Normal coagulation test results were confirmed until 3 weeks after HSCT (Fig. 1). A complete remission of lymphoma was achieved. While tacrolimus was tapered off at the end of 2009, a gradual increase in the patient's lymphocyte count was observed. At four months after the cessation of tacrolimus, the patient developed mild thrombocytopenia $\left(<100 \times 10^{3} / \mu \mathrm{L}\right)$ and lichenoid changes in the oral mucosa and progressive depigmentation of the fingers; these findings were diagnosed as manifestations of chronic GVHD. There were no other noteworthy findings in the digestive tract, liver, lung or joints at this time. Biopsies were not performed. At seven months after the cession of tacrolimus, bone marrow aspiration was performed to investigate the cause of persistent thrombocytopenia; the microscopic findings included normocellularity (nucleated cell count of 189x $\left.10^{3} / \mu \mathrm{L}\right)$ and an increased megakaryocyte count $(81 / \mu \mathrm{L})$ without any signs of relapse of the lymphoma or hemophagocytosis, which was evidence of increased peripheral consumption. At three days after bone marrow aspiration, the patient noticed acute swelling of his left lower-leg. The activated partial thromboplastin time (aPTT) was prolonged to $95 \mathrm{~s}$ (normal range, 24.8-38.1 seconds). Computed tomography (CT) showed bilateral pulmonary embolism (Fig. 2A) and left iliofemoral vein thrombosis (Fig. 2B). Careful screening led us to suspect the onset of APS, and LAC positivity was 


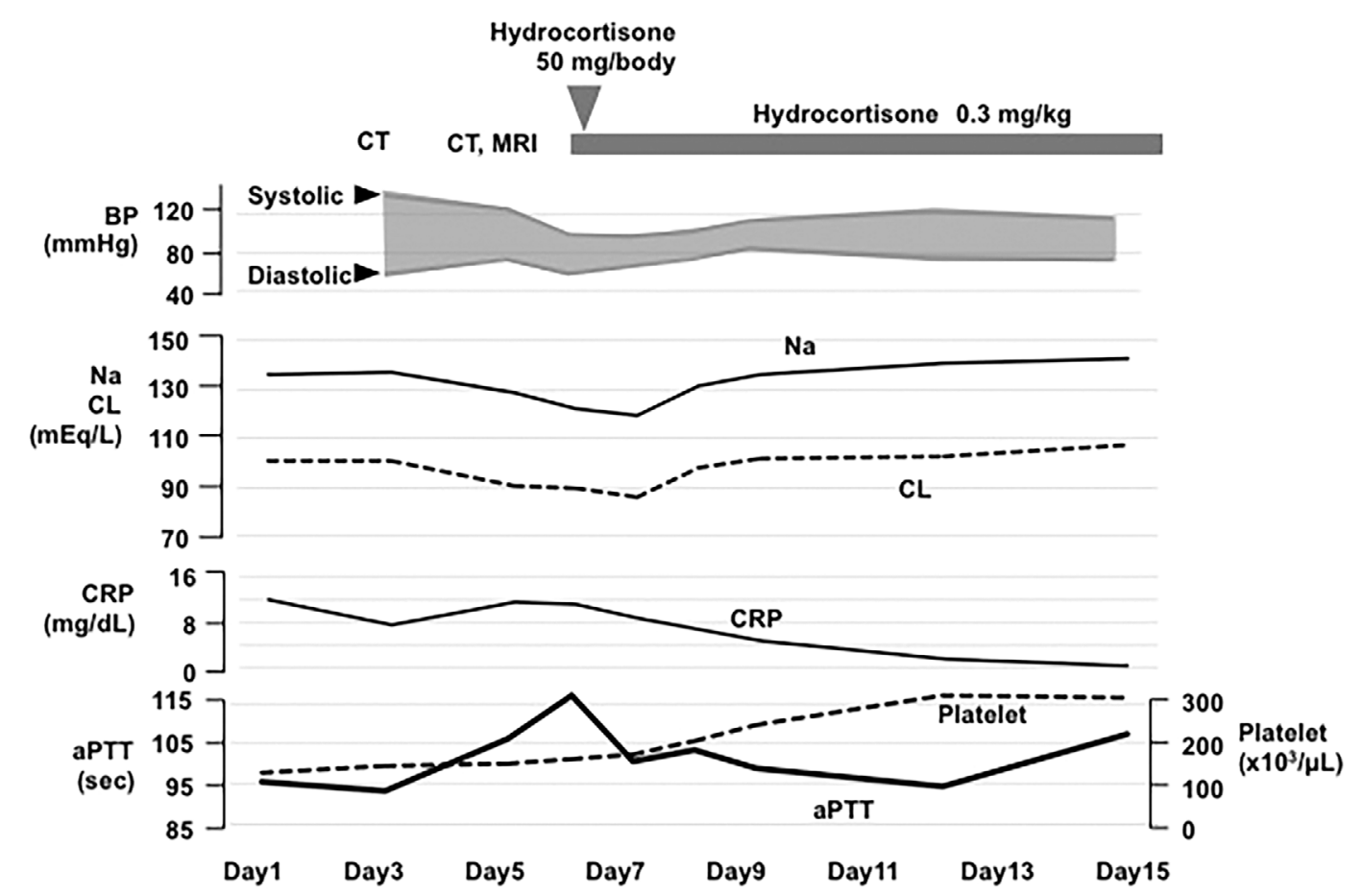

Figure 3. The clinical course during the episode of adrenal hemorrhage in 2015 . The day of presentation due to upper respiratory infectious symptoms was arbitrarily defined as Day 1. CT: computed tomography, MRI: magnetic resonance imaging, BP: blood pressure, Na: sodium, CL: chloride, CRP: C-reactive protein, aPTT: activated partial thromboplastin time

confirmed by the mixing test, a dilute Russell's viper venom test time ratio of $2.4(<1.3)$, and a phospholipid neutralization test time of 64.1 seconds $(<6.3)$. A low level of antinuclear antibodies $(\times 80)$ was detected, but the patient's serum was negative for anti-beta-2 glycoprotein I (GPI) antibodies $(<1.2 \mathrm{U} / \mathrm{mL})$ and aCL. The lymphocyte count increased to $4,804 / \mu \mathrm{L}$ (Fig. 1). He underwent inferior vena cava filter replacement on the day of admission, and anticoagulant therapy was started with the continuous intravenous infusion of heparin (aPTT controlled to 1.5-2.5 times the control value) and oral warfarin. The local intravenous administration of urokinase via a catheter from the left popliteal vein and the peripheral vein (as appropriate) was also performed for 5 days after admission. After confirming the improvement of left iliofemoral vein thrombosis, the catheter was extracted. Eight days later, the CT findings showed a reduction of the pulmonary embolism; thus, the inferior vena cava filter was also removed. The pathological evaluation of the blood clot was negative for malignancy. At a 41-week interval, with a time lag of $>12$ weeks required for reevaluation, a second positive LAC result confirmed the diagnosis of APS. Reassessment of the donor showed that the aPTT was 32.1 seconds, and the patient's serum was negative for LAC, suggesting that APS was not induced by transmission from the donor. Tacrolimus was re-administered to treat chronic GVHD until the end of 2013, and although the depigmentation on the fingers remained, the lichenoid changes of the oral mucosa were alleviated. The administration of warfarin was continued as anticoagulant therapy.
In 2015, the patient presented with rhinorrhea, cough, and sore throat (Day 1) (Fig. 3). He was admitted to the hospital on Day 3 for right-sided abdominal pain, which was reduced by sitting upright (Fig. 3). He also complained of nausea and appetite loss. He had no fever, and his blood pressure was $135 / 58 \mathrm{mmHg}$ (Fig. 3). No petechiae/purpura were detected on the patient's extremities. Mild tenderness in the upper-abdominal region was observed. The laboratory data on Day 3 showed that the platelet count had slightly decreased to $128 \times 10^{3} / \mu \mathrm{L}$, the PT/INR on warfarin therapy was 1.97 , the aPTT was prolonged to 98.5 seconds, which had also been documented in a regular visit, 10 days prior to the patient's admission (PT/INR of 1.88 and aPTT of 87.6 seconds). A mixing test was positive for LAC. The patient then developed general fatigue. On Day 5, the patient showed hypotension, with a blood pressure of 95/64 $\mathrm{mmHg}$, and the laboratory data revealed a fasting blood sugar level of $82 \mathrm{mg} / \mathrm{dL}$, a serum sodium level of $119 \mathrm{mmol} / \mathrm{L}$, a serum C-reactive protein (CRP) level of $11.75 \mathrm{mg} / \mathrm{dL}$, and an aPTT of 112.7 seconds (Fig. 3). An infusion of normal saline and glucose was started. Rapid influenza antigen and adenovirus antigen tests were negative. Microbial tests, including blood cultures, serum (1-3)-beta-D glucan, serum galactomannan, cryptococcal antigen, and interferon-gamma release assays for tuberculosis were all negative. CT showed no abnormalities on Day 3 (Fig. 4A); however, the findings of repeated CT (at a 48-hour interval; Fig. 4B) and magnetic resonance imaging (MRI) (Fig. 4C) were compatible with massive bilateral adrenal hemorrhage. CT and MRI revealed 

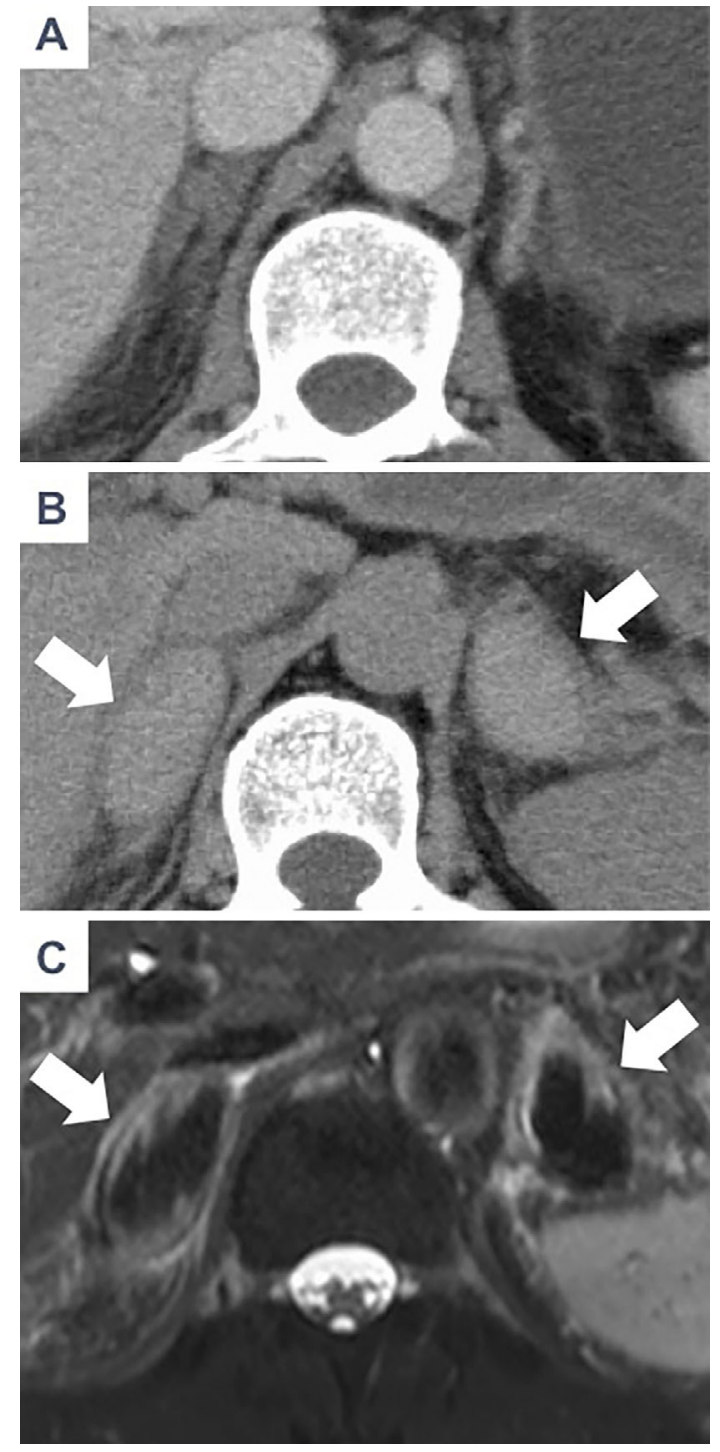

Figure 4. The results of imaging of the bilateral adrenal glands. (A) Computed tomography revealed no abnormality of the adrenal glands on Day 3. (B) The enlargement of the bilateral adrenal glands (white arrows) was evident on Day 5. (C) Axial T2-weighted magnetic resonance imaging (MRI) revealed a region of low signal intensity (white arrows).

no findings that suggested infection (i.e., pneumonia or abscess). On Day 5, an endocrinal examination revealed a low cortisol concentration of $1.9 \mu \mathrm{g} / \mathrm{mL}$ (normal range, 4-19.3 $\mu \mathrm{g} / \mathrm{mL}$ ) and an adrenaline concentration of $<5 \mathrm{pg} / \mathrm{mL}$ (normal range, 6-100 pg/mL); the patient's aldosterone concentration was $65.4 \mathrm{pg} / \mathrm{mL}$ and was within the normal range (29.9-159 $\mathrm{pg} / \mathrm{mL})$. The adrenocorticotropic hormone (ACTH) level was elevated to $108 \mathrm{pg} / \mathrm{mL}$ (normal range, 7.2-63.3 pg/mL). These findings were consistent with the destruction of the adrenal cortex and medulla due to adrenal hemorrhage. Replacement therapy with hydrocortisone was started from Day 6 and resulted in the dramatic improvement of both the hypotension and hyponatremia (Fig. 3). The platelet count and the aPTT had returned to the levels that were measured before the onset of adrenal hemorrhage, while the serum D-dimer levels were $0.8-1.0 \mu \mathrm{g} / \mathrm{mL}$ and the
PT/INR was 2.11 on Day 3 and 2.08 on Day 5 (with warfarin therapy). After Day 15, a maculopapular rash developed on the patient's trunk and thighs, and a biopsy specimen revealed basal layer vacuolization, spongiosis, and perivascular lymphocytic infiltration, compatible with skin GVHD. These lesions were alleviated with the use of steroid creams and the dose of hydrocortisone was adjusted from 0.3 to $0.4 \mathrm{mg} / \mathrm{kg}$ based on the ACTH levels. The patient was discharged with the oral administration of warfarin as anticoagulant therapy, and hydrocortisone as glucocorticoid replacement therapy. The patient remained in good health without bleeding or thrombotic complications for the 2 years until the writing of this report, and there has been no recurrence of chronic GVHD symptoms, despite the fact that the patient has not been treated with immunosuppressive agents (calcineurin inhibitors).

\section{Discussion}

The patient in the present case was diagnosed with APS based on positive LAC results on two or more occasions at least 12 weeks apart and the clinical diagnosis of thromboembolism; the patient's condition was subsequently complicated with bilateral adrenal hemorrhage. There are only six reported case of definitive APS with clinical thrombosis after allogeneic HSCT (5-10) (Table). In five of the cases (including the present case), peripheral blood was the stem cell source, four had thrombosis during acute GVHD, and the other three developed APS during chronic GVHD. The present case showed that the initial thrombotic episode of APS developed after the onset of chronic GVHD while tacrolimus was being tapered off. The underlying mechanisms of autoimmune disease after HSCT that could explain the present clinical course are as follows: GVHD-induced thymic damage compromised the immune tolerance during de novo lymphopoiesis after HSCT (11). While tapering off tacrolimus, the patient in the present case showed an increase in his total lymphocyte count; thus, we hypothesize that the development of autoreactive lymphocytes might have triggered the onset of APS. CMV reactivation was another factor that was documented in the present case that may have induced APS, as it is reported to be correlated with LAC positivity (12). The patient also possessed an HLA-DRB1*0901 allele, which is associated with beta-2 GPI-dependent aCL positivity in Japanese patients with systemic lupus erythematosus (SLE) (13). Although our patient was negative for aCL, the HLA-DRB1 allele might have been associated with the expression of antigen to $\mathrm{CD}^{+} \mathrm{T}$ helper cells, which might have resulted in the production of LAK.

In an 86-case series of acute adrenal hemorrhage caused by primary APS, SLE or SLE like conditions, the patients showed the following symptoms: abdominal pain (55\%), nausea or vomiting (31\%), hypotension (54\%), and bilateral involvement (77\%); elevated CRP levels were often noted (14). All of these findings seemed to be consistent 
Table. Collected Case Reports of Thrombotic Complications Due to Antiphospholipid Antibody Syndrome after Allogeneic Stem Cell Transplantation.

\begin{tabular}{|c|c|c|c|c|c|c|c|c|}
\hline $\begin{array}{l}\text { Age at APS/ } \\
\text { gender }\end{array}$ & Disease & Donor & Source & GVHD & $\begin{array}{c}\text { Onset after } \\
\text { HSCT }\end{array}$ & $\begin{array}{c}\text { Thrombotic } \\
\text { event }\end{array}$ & Outcome & $\begin{array}{c}\text { Reference } \\
\text { number }\end{array}$ \\
\hline $\begin{array}{l}4 \text { months/ } \\
\text { male }\end{array}$ & Omen syndrome & $\begin{array}{l}\text { HLA-matched } \\
\text { sibling }\end{array}$ & PB & Acute & Day 59 & $\begin{array}{l}\text { Focal seizures, } \\
\text { hemiplegia, } \\
\text { pulmonary } \\
\text { embolism }\end{array}$ & $\begin{array}{l}\text { Residual } \\
\text { hemiplegia }\end{array}$ & 5 \\
\hline 37/male & $\begin{array}{l}\text { Acute } \\
\text { myelogenous } \\
\text { leukemia }\end{array}$ & $\begin{array}{l}\text { HLA-matched } \\
\text { sibling }\end{array}$ & PB & Acute & Day 23 & $\begin{array}{l}\text { Veno-occlusive } \\
\text { disease }\end{array}$ & Death & 6 \\
\hline $54 / \mathrm{male}$ & $\begin{array}{l}\text { Chronic } \\
\text { myelomonocytic } \\
\text { leukemia }\end{array}$ & Sibling & ND & Chronic & 7 months & $\begin{array}{l}\text { Veno-occlusive } \\
\text { disease }\end{array}$ & $\begin{array}{l}\text { No } \\
\text { improvement }\end{array}$ & 7 \\
\hline 44/female & $\begin{array}{l}\text { Acute } \\
\text { lymphoblastic } \\
\text { leukemia }\end{array}$ & $\begin{array}{l}\text { HLA-matched } \\
\text { sibling }\end{array}$ & $\begin{array}{l}\text { PB (T } \\
\text { deplete) }\end{array}$ & Acute & 7 months & $\begin{array}{l}\text { Acute infarction } \\
\text { with hemorrhage } \\
\text { in the posterior } \\
\text { cerebral artery } \\
\text { territory }\end{array}$ & Death & 8 \\
\hline 10/male & Thalassemia & $\begin{array}{l}\text { HLA-matched } \\
\text { sibling }\end{array}$ & PB & Acute & Day 338 & Ischemic stroke & $\begin{array}{l}\text { Complex } \\
\text { partial seizure }\end{array}$ & 9 \\
\hline 24/male & $\begin{array}{l}\text { Chronic } \\
\text { myelogenous } \\
\text { leukemia }\end{array}$ & $\begin{array}{l}\text { HLA-1 locus } \\
\text { mismatched } \\
\text { sibling }\end{array}$ & $\mathrm{BM}$ & Chronic & 53 months & $\begin{array}{l}\text { Cerebrovascular } \\
\text { thrombosis }\end{array}$ & $\begin{array}{l}\text { Complete } \\
\text { recovery }\end{array}$ & 10 \\
\hline 56/male & $\begin{array}{l}\text { Follicular } \\
\text { lymphoma }\end{array}$ & $\begin{array}{l}\text { HLA matched } \\
\text { sibling }\end{array}$ & PB & $\begin{array}{l}\text { Acute/ } \\
\text { chronic }\end{array}$ & 45 months & $\begin{array}{l}\text { Deep vein } \\
\text { thrombosis, } \\
\text { pulmonary } \\
\text { embolism }\end{array}$ & $\begin{array}{l}\text { Under } \\
\text { controllable }\end{array}$ & $\begin{array}{l}\text { Present } \\
\text { case }\end{array}$ \\
\hline
\end{tabular}

APS: antiphospholipid syndrome, GVHD: graft-versus-host disease, HSCT: hematopoietic stem cell transplantation, PB: peripheral blood, BM: bone marrow, ND: not described

with the current presentation. Adrenal hemorrhage developed following infectious episodes in 11 of 86 reported patients (14). The upper-respiratory infection was also a trigger of subsequent events in the present case. For the differential diagnosis, Waterhouse-Friderichsen syndrome, tuberculosis, cryptococcosis, and a relapse of lymphoma were considered; however, no pathogens was detected, and the patient has been in complete remission from lymphoma for 2 years since the episode of bilateral adrenal hemorrhage. Thus, we concluded that the cause of bilateral adrenal hemorrhage was directly associated with APS. Infectious agents generally bind to the receptors of cells that are accosted by the innate immune system and which activate the adaptive immune response, resulting in the activation of potentially autoreactive lymphocyte clones (15); which might have influenced the progression of APS.

The initiating event of adrenal hemorrhage in APS is hypothesized to be microembolism in the adrenal vein, which is followed by intra-adrenal vascular collapse, resulting in massive hemorrhage (16). We hypothesize that the slightly low platelet count and the prolonged aPTT at the time of adrenal hemorrhage were caused by the hypercoagulable state of APS based on the preceding infection. Judging from the steady state of the serum D-dimer levels, there was no massive thrombosis; however, we hypothesize that a microthrombosis had formed in the adrenal veins due to the progression of the hypercoagulable state of APS followed by the collapse of the intra-adrenal vessels. A time lag between the onset of symptoms, including abdominal pain, nausea and appetite loss on Day 3, and the adrenal hemorrhage that was observed on CT on Day 5 might demonstrate that this microthrombosis was not evaluable on CT studies and that it progressed to the rupture of adrenal veins and resulted in hyponatremia.

As the present case showed, adrenal hemorrhage is frequently bilateral (14); thus, in addition to being an issue with respect to hypercoagulation, the immunological effects of aPL against the late endosomes of the bilateral adrenal glands have also been proposed (17). Shortly after starting hydrocortisone, the CRP levels decreased as the aPTT and the platelet count improved; thus, we hypothesized that hydrocortisone had successfully controlled the inflammation caused by the infection and alleviated the patient's adrenal insufficiency. It has been reported that approximately 50\% of patients with adrenal hemorrhage caused by APS have continued with anticoagulant therapy, resulting in a favorable prognosis (14). On the other hand, new thrombotic events were recorded in 10 of 21 patients who did not receive prolonged anticoagulant therapy (14). A total 25 of 69 patients died and the causes of death were non-inflammatory thrombotic microangiopathy with multiorgan failure in 14 patients (14). Thus, we continued warfarin therapy during and after the episode of adrenal hemorrhage in order to prevent secondary thromboembolism.

Actually, thrombocytopenia is frequently associated with chronic GVHD. However, thrombocytopenia in APS is re- 
ported to be a thrombotic risk factor (18), which is relevant to our patient as thrombocytopenia was present prior to the onset of deep vein thrombosis as well as adrenal hemorrhage. Thus, when a patient displays thrombocytopenia as well as LAK positivity during chronic GVHD, physicians should be highly alert to he possible development of thrombotic complications.

To the best of our knowledge, this is the first report of bilateral adrenal hemorrhage as a complication of APS during the development of chronic GVHD. Steroid replacement therapy in addition to anticoagulant therapy resulted in a favorable long-term outcome in the patient, who was an HSCT recipient. We recommend that careful examinations be performed when a patient with chronic GVHD shows thrombocytopenia and a prolonged aPTT. Once the diagnosis of APS has been confirmed, the clinical manifestations of adrenal insufficiency should never be overlooked in patients with an acute infectious episode.

The authors state that they have no Conflict of Interest (COI).

\section{Acknowledgement}

We appreciate the medical and nursing staff at the JCHO Kyushu Hospital.

\section{References}

1. Holbro A, Abinun M, Daikeler T. Management of autoimmune diseases after haematopoietic stem cell transplantation. $\mathrm{Br} \mathrm{J}$ Haematol 157: 281-290, 2012.

2. Ruiz-Irastorza G, Crowther M, Branch W, Khamashta MA. Antiphospholipid syndrome. Lancet 376: 1498-1509, 2010.

3. Greeno EW, Haake R, McGlave P, Weisdorf D, Verfaillie C. Lupus inhibitors following bone marrow transplant. Bone Marrow Transplant 15: 287-291, 1995.

4. Quaranta S, Shulman H, Ahmed A, et al. Autoantibodies in human chronic graft-versus-host disease after hematopoietic cell transplantation. Clin Immunol 91: 106-116, 1999.

5. Qasim W, Gerritsen B, Veys P. Anticardiolipin antibodies and thromboembolism after BMT. Bone Marrow Transplant 21: 845847, 1998.

6. Morio $\mathrm{S}$, Oh $\mathrm{H}$, Hirasawa $\mathrm{A}$, et al. Hepatic veno-occlusive disease in a patient with lupus anticoagulant after allogeneic bone marrow transplantation. Bone Marrow Transplant 8: 147-149, 1991.

7. Sõhngen D, Heyll A, Meckenstock G, et al. Antiphospholipid syndrome complicating chronic graft-versus-host disease after allogeneic bone marrow transplantation. Am J Hematol 47: 143-144, 1994.

8. Kasamon KM, Drachenberg CI, Rapoport AP, Badros A. Catastrophic antiphospholipid syndrome: atypical presentation in the setting of chronic graft versus host disease: case report and review of the literature. Haematologica 90: ECR17, 2005.

9. Sirachainan N, Pakakasama S, Hongeng S, Chuansumrit A, Tuntiyatorn L, Vilaiyuk S. Antiphospholid antibody syndrome and $\mathrm{Hb}$ E/Beta thalassemia disease post-allogeneic stem cell transplantation. Pediatr Blood Cancer 57: 153-156, 2011.

10. Ritchie DS, Sainani A, D'Souza A, Grigg AP. Passive donor-torecipient transfer of antiphospholipid syndrome following allogeneic stem-cell transplantation. Am J Hematol 79: 299-302, 2005.

11. Krenger W, Blazar BR, Holländer GA. Thymic T-cell development in allogeneic stem cell transplantation. Blood 117: 6768-6776, 2011.

12. Mengarelli A, Minotti C, Palumbo G, et al. High levels of antiphospholipid antibodies are associated with cytomegalovirus infection in unrelated bone marrow and cord blood allogeneic stem cell transplantation. Br J Haematol 108: 126-131, 2000.

13. Hashimoto H, Yamanaka K, Tokano Y, et al. HLA-DRB1 alleles and beta 2 glycoprotein I-dependent anticardiolipin antibodies in Japanese patients with systemic lupus erythematosus. Clin Exp Rheumatol 16: 423-427, 1998.

14. Espinosa G, Santos E, Cervera R, et al. Adrenal involvement in the antiphospholipid syndrome: clinical and immunologic characteristics of 86 patients. Medicine 82: 106-118, 2003.

15. Mortensen ES, Fenton KA, Rekvig OP. Lupus nephritis: the central role of nucleosomes revealed. Am J Pathol 172: 275-283, 2008.

16. Yap AS, Powell EE, Yelland CE, Mortimer RH, Perry-Keene DA. Lupus anticoagulant. Ann Intern Med 111: 262-263, 1989.

17. Berneis K, Buitrago-Téllez C, Müller B, Keller U, Tsakiris DA. Antiphospholipid syndrome and endocrine damage: why bilateral adrenal thrombosis? Eur J Haematol 71: 299-302, 2003.

18. Hisada R, Kato M, Sugawara E, et al. Thrombotic risk stratification by platelet count in patients with antiphospholipid antibodies: a longitudinal study. J Thomb Haemost 15: 1782-1787, 2017.

The Internal Medicine is an Open Access article distributed under the Creative Commons Attribution-NonCommercial-NoDerivatives 4.0 International License. To view the details of this license, please visit (https://creativecommons.org/licenses/ by-nc-nd/4.0/).

(C) 2018 The Japanese Society of Internal Medicine Intern Med 57: 1439-1444, 2018 